\title{
Post-concussion syndrome among patients experiencing head injury attending emergency department of Hawassa University Comprehensive specialized hospital, Hawassa, southern Ethiopia
}

\author{
Asres Bedaso* (D), Ephrem Geja, Mohammed Ayalew, Zewdie Oltaye and Bereket Duko
}

\begin{abstract}
Introduction: Post-concussion syndrome (PCS) is defined as the presence of 3 or more of the following signs and symptoms after experiencing head injury such as headache, dizziness, fatigue, irritability, insomnia, difficulty of concentration or memory difficulty. In Ethiopia, even though there was no research conducted on post-concussion syndrome, it is common health problems after experiencing head trauma that affect the productive age group, which directly or indirectly influences the development of the country.

Objective: To assess the prevalence and determinants of post-concussion syndrome among patients experiencing head injury attending emergency department of Hawassa University Comprehensive Specialized hospital, Hawassa, Southern Ethiopia.

Methods: Institution based cross sectional study was conducted from November 1, 2017 to March 30, 2018, in Hawassa University Comprehensive Specialized Hospital emergency department, Hawassa, Southern Ethiopia.

Result: A total of 275 cases were interviewed during data collection period with response rate of $95.2 \%$. More than half (55.7\%) of patients were within age range of 25-34 and Majorities (55.6\%) of patients were married. About two-fifths of study participants (41.5\%) had at least three symptoms of post-concussion syndrome components. Headache and restlessness were the most symptoms occurring in varying severity while double vision and fatigue were less severe among others. Occupation, cause of injury and location of injury were significant determinants of post-concussion syndrome.
\end{abstract}

Conclusion: About $41.5 \%$ of study participants had at least three symptoms of PCS. Occupation, cause of injury and location of injury were significantly associated with the occurrence of PCS.

Keywords: Post-concussion syndrome, Mild traumatic brain injury, Head injury, Hawassa

\footnotetext{
* Correspondence: asresbedaso@gmail.com

College of Medicine and Health Sciences, School of Nursing, Hawassa

University, P.O.BOX: 1560 Hawassa, Ethiopia
}

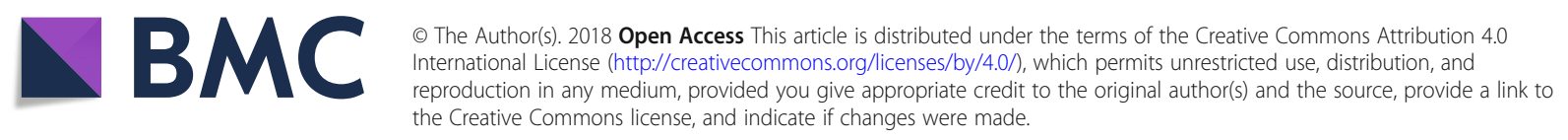




\section{Introduction}

According to World Health Organization (WHO) Post -concussion syndrome (PCS) is defined as the presence of 3 or more of the following signs and symptoms after experiencing head injury such as headache, dizziness, fatigue, irritability, insomnia, difficulty of concentration, or memory difficulty [1].The diagnosis of PCS is made in people who have suffered with a head trauma when persistent post-traumatic amnesia, loss of consciousness, or post-traumatic seizures and neuropsychological impairment must be present for three months after the injury which must have been absent or less severe before the injury [2].

PCS is one of the commonest neuropsychiatric consequence after having traumatic brain injury (TBI) [3] and its onset is more often for the period of the first month after trauma, but it may continue for months even years or more after head trauma [1,3]. The magnitude of PCS differs, however most studies reported that about $15 \%$ of individuals with a history of a single concussion develop persistent symptoms associated with the injury and these symptoms may continue last for more than three months after the head injury [4]. However, there is substantial risk of misdiagnosis of PCS, because most of the symptoms related to PCS are common or may be worsen by other disorders. For example; headaches that occur after a concussion may feel like migraine or tension-type headaches [5].

Some of the risk factors that have been associated with PCS are pre-existing medical or psychological conditions, expectations of disability, being female and older age. Physiological and psychological factors present before, during, and after the injury are all thought to be involved in the development of PCS [6] and the questions of the cause or causes of PCS have been a lot debated for many years and remain controversial [7]. Some experts found out that post-concussion symptoms are caused by structural damage to the brain or disruption of neurotransmitter systems [8]. Though, about $38 \%$ of people who experience a head injury with symptoms of concussion had no radiological evidence of brain lesions [9].

In addition, about $10 \%$ of people with PCS develop sensitivity to light or noise, about $5 \%$ experience a decreased sense of taste or smell, and about $14 \%$ report blurred vision [10] and some people may also have double vision or ringing in the ears [11].

Post-concussion syndrome (PCS), the most common entity to be diagnosed in people who have experienced TBI, is a constellation of physical, cognitive, emotional, and behavioral symptoms and its prevalence varies from $11 \%$ to $64 \%$ [12]. The prevalence of persistent symptoms at 1 year is not known, but is estimated to be $5 \%$. There is limited information on the prevalence and incidence of PCS in children. Despite the prevalence of PCS, uncertainty exists about the validity of this diagnosis because behavioral disturbances frequently occur in children after any injury and because factors present before injury and medico legal concerns after injury may influence recovery [13]. Up to $60 \%$ of patients with minor traumatic brain injury (MTBI) will suffer from post-concussion syndrome (PCS) characterized by persistence of symptoms such as headache, fatigue, memory difficulties and emotional liability [14].

According to different researches which were done worldwide, head injuries are common health problems of the world which affects mainly productive age groups of the world and contributes strongly to costs in the health care system. In Africa, head injuries are the common health problems and are substantial causes for morbidity and mortality which mostly affects productive age group of the population and brings economic consequences for both individuals and society of the continent [15].

In Ethiopia, even though there was no research conducted on post-concussion syndrome, it is a common health problem that affect the productive age group, which directly or indirectly influences the development of the country [16]. So, since the problem affects the productive age group of the country, paying attention to carry out this study assessing the magnitude and determinants of post-concussion syndrome is most crucial.

\section{Methods}

\section{Study design, study area and study period}

Institutional based cross-sectional study was conducted in Emergency department of Hawassa University Comprehensive and Specialized Hospital (HUCSH), from November 1, 2017 to March 30, 2018 which is found in Hawassa city $273 \mathrm{Km}$ far south from Addis Ababa. HUCSH started giving service since 2005 and serves for more than 18 million people of the catchment area, from the southern region and the surrounding Oromia zones. The hospital had 400 beds for inpatient service and also gives different outpatient services.

\section{Population}

All patients presented to adult emergency department of HUCSH with head trauma were the source population and all head injury patients presented to adult emergency department in HUCSH during the study period were the study population.

\section{Inclusion and exclusion criteria}

All patients experiencing head injury whose age 18 year or above were included in the study and patients 
who were severely ill or unconscious were excluded from the study.

\section{Sample size and sampling technique}

The sample size was determined using single population proportion formula considering the following assumptions: confidence interval $(\mathrm{CI})$ of $95 \%(Z=1.96)$, absolute precision or tolerable margin of error $(d=0.05)$, and anticipated proportion of patients who experience PCS $=50 \%(P)$. Since the source population was $<10,000$, we used a correction formula, adding $10 \%$ non-response rate the final sample size was 289. Consecutive sampling technique was used to select the respondents for interview.

\section{Data collection instrument}

In order to assess symptoms after experiencing head injury, a number of measures have been described. One commonly used tool is the Rivermead Post-Concussion Symptoms Questionnaire (RPQ), which has demonstrated reliability and validity $[17,18]$. This questionnaire takes into account the high background prevalence of symptoms by asking the patients not only if symptoms are present, but also to rate the intensity of each of 16 symptoms as compared to before the Mild Traumatic Brain injury (MTBI).

\section{Data quality control measures}

The data was collected by trained nurse professionals and supervised by two emergency and critical care nurse specialists. The questionnaire was pre tested on $5 \%$ of the study participant prior to the actual data collection period for its clarity, understandability and completeness. The data collected during the pre-test was not included in the final analysis.

\section{Data processing and analysis}

The collected data were checked cleaned, coded and entered and analyzed using SPSS version 21. Descriptive statistical analysis was used to estimate the frequencies and percentages of the variables. Bivariate and multivariate logistic regression analysis was used to see the association between outcome and explanatory variables. The strength of the association was measured by odds ratio with 95\% CI and $P$-value less than 0.05 was considered as statistically significant.

\section{Results}

A total of 275 cases were interviewed over five months data collection period with final response rate of $95.2 \%$. More than half $(55.7 \%)$ of patients were in age range of 25-34. Majorities (55.6\%) of patients were married and $74.9 \%$ were living with family (Table 1 ).
Table 1 Socio-demographic characteristics of study participants attending emergency outpatient department of HUCSH, Hawassa, Southern Ethiopia $(n=289)$

\begin{tabular}{|c|c|c|c|}
\hline Characteristics & Categories & Number & Percent \\
\hline \multirow[t]{5}{*}{$\overline{\text { Age }}$} & $18-24$ & 61 & 22.2 \\
\hline & $25-29$ & 100 & 36.4 \\
\hline & $30-34$ & 53 & 19.3 \\
\hline & $35-39$ & 38 & 13.8 \\
\hline & $40+$ & 23 & 8.4 \\
\hline \multirow[t]{2}{*}{ Sex } & Male & 161 & 58.5 \\
\hline & Female & 114 & 41.5 \\
\hline \multirow[t]{5}{*}{ Religion } & Orthodox & 99 & 36.0 \\
\hline & Muslim & 64 & 23.3 \\
\hline & Protestant & 89 & 32.4 \\
\hline & Catholic & 22 & 8.4 \\
\hline & Other & 1 & 0.4 \\
\hline \multirow[t]{4}{*}{ Marital status } & Single & 105 & 38.2 \\
\hline & Married & 153 & 55.6 \\
\hline & Divorced & 6 & 2.2 \\
\hline & Widowed & 11 & 4.0 \\
\hline \multirow[t]{6}{*}{ Occupation } & $\begin{array}{l}\text { Government } \\
\text { employee }\end{array}$ & 84 & 30.5 \\
\hline & Merchant & 72 & 26.2 \\
\hline & Farmer & 34 & 12.4 \\
\hline & Student & 44 & 16. \\
\hline & Daily labor & 15 & 5.5 \\
\hline & House wife & 26 & 9.5 \\
\hline \multirow[t]{5}{*}{ Educational status } & $\begin{array}{l}\text { Unable to read } \\
\text { and write }\end{array}$ & 43 & 15.6 \\
\hline & $\begin{array}{l}\text { Able to read } \\
\text { and write }\end{array}$ & 39 & 14.2 \\
\hline & Primary & 31 & 11.3 \\
\hline & Secondary & 141 & 51.3 \\
\hline & College and above & 21 & 7.6 \\
\hline \multirow[t]{7}{*}{ Ethnicity } & Sidama & 104 & 37.8 \\
\hline & Wolaita & 35 & 12.7 \\
\hline & Amhara & 39 & 14.2 \\
\hline & Oromo & 62 & 22.5 \\
\hline & Tigre & 2 & 0.7 \\
\hline & Gurage & 19 & 6.9 \\
\hline & Others & 14 & 5.1 \\
\hline \multirow[t]{2}{*}{ Living condition } & With family & 206 & 74.9 \\
\hline & Alone & 69 & 25.1 \\
\hline
\end{tabular}




\section{Social support and causes of injury}

From the total study participants $31.6 \%$ of respondents have very good social support (Additional file 1).43.6\% of study participants get injured due to motor bicycle accident (Additional file 2).

\section{Characteristics of injury and symptoms of PCS}

From the study participants $65.1 \%$ had $<1$ week duration of illness and $30.9 \%$ faced injury on the right lateral part of their brain (Table 2). Among the study participants $227(82.5 \%)$ complains headache as a major symptom of PCS (Additional file 3).

\section{Prevalence of post-concussion syndrome}

We computed total score from 16 items, each measured from zero to four. All values were summed, with expected value from 0 to 64 . The finding showed that mean of 7.57 with $\mathrm{SD} \pm 2.63$. In this study the overall prevalence of post-concussion syndrome is $41.5 \%$.

\section{Factors associated with PCS}

During Multivariate logistic regression being student $(P=0.04$, CI $[0.14,0.95])$, Motor bicycle as a cause of injury $(P=0.04, \mathrm{CI}[0.30,0.98])$ and location of head

Table 2 Characteristics of injures of study participants attending emergency outpatient department of Hawassa University compressive specialized hospital, Hawassa, Southern Ethiopia $(n=289)$

\begin{tabular}{llll}
\hline Characteristics & Categories & Number & Percent \\
\hline Duration of illness & $<1$ week & 179 & 65.1 \\
& 1-2 weeks & 55 & 20.0 \\
& 34 weeks & 32 & 11.6 \\
& $>1$ month & 9 & 3.3 \\
Location of head injury & Right lateral & 85 & 30.9 \\
& Left lateral & 86 & 31.3 \\
& Frontal & 75 & 27.3 \\
& Other site & 29 & 10.5 \\
Clinical presentation & Shock & 55 & 20.0 \\
at time of admission & Unconscious & 115 & 41.8 \\
& Bleeding & 77 & 28.0 \\
& Other & 28 & 10.2 \\
Length of stay in hospital & $<5$ days & 108 & 39.3 \\
& 1 week & 87 & 31.6 \\
& 2-4 weeks & 61 & 22.2 \\
& 5+ weeks & 19 & 6.9 \\
& $<1$ week & 123 & 44.7 \\
& 1-5 weeks & 115 & 41.8 \\
& 6-10 weeks & 26 & 9.5 \\
Duration of treatment & 10+ weeks & 11 & 4.0 \\
\hline
\end{tabular}

injury $(P=0.02$, CI $[0.09,0.83])$ were significantly associated with post-concussion syndrome (Table 3).

\section{Discussion}

This study was designed to assess prevalence of PCS and its associated factors among patients experiencing head injury and attending emergency department in Hawassa university comprehensive specialized hospital in 2018.

The Overall prevalence of PCS among patients experiencing head injury and attending emergency department in Hawassa university comprehensive specialized hospital was $41.5 \%$. The finding of this study was higher than study done in New Zealand where more than $30 \%$ of participants reported PCS symptoms [19]. In addition it was significantly higher as compared to Malaysian [20] and Swedish [21] study which was $8.1 \%$ and $34 \%$ of patients survived from mild TBI developed PCS, respectively. The variation between the current study and the study mentioned above might be due to the difference in sample size, studies area and socioeconomic difference among study participants.

Students were $36 \%$ less likely to develop PCS compared to government employee. As it was evidenced, among study participants who experience head injury $30.5 \%$ and $16 \%$ were government employee and students by occupation respectively. This implies those who experienced head injury are more likely to develop PCS. Also, as it was commonly observed in the study area government employees uses motor bicycle compared with students, which will increase risk of road traffic accident.

Patients injured by motor bicycle were $54 \%$ less likely to develop PCS compared with those injured due to car accident. This might be due to the fact that it is obligatory to use helmets by motor bicycle drivers which protect them from head injury.

Patients who injured occipital area of the brain were $28 \%$ less likely to develop PCS compared to with those who injured on right lateral. This finding is also supported by the follow up study conducted in USA, study participants who injured on fronto temporal and parietal area were severely affected and atrophied because of head injury compared with injuries on the different part of the brain [22].

\section{Conclusion}

About $41.5 \%$ of study participants had at least three symptoms of PCS. Occupation, cause of injury and location of injury were significantly associated with the occurrence of PCS. 
Table 3 Factors Associated PCS (Bivariate and Multivariate logistic regression) of study participants attending emergency outpatient department of Hawassa university compressive specialized hospital, Hawassa, Southern Ethiopia $(n=289)$

\begin{tabular}{|c|c|c|c|c|c|}
\hline \multirow[t]{2}{*}{ Variable } & \multicolumn{2}{|c|}{ PCS } & \multirow{2}{*}{$\begin{array}{l}\text { COR } \\
(95 \% \mathrm{Cl})\end{array}$} & \multirow{2}{*}{$\begin{array}{l}\text { AOR } \\
(95 \% \mathrm{Cl})\end{array}$} & \multirow{2}{*}{$\begin{array}{l}P \text { - } \\
\text { Value }\end{array}$} \\
\hline & No & $\overline{\text { Yes }}$ & & & \\
\hline \multicolumn{6}{|l|}{ Age } \\
\hline $18-24$ & 38 & 23 & 1 & 1 & \\
\hline $25-29$ & 64 & 36 & $0.9(0.48-1.79)$ & $0.61(0.28-1.35)$ & 0.22 \\
\hline $30-34$ & 32 & 21 & $1.08(0.51-2.31)$ & $0.66(0.26-1.70)$ & 0.39 \\
\hline $35-39$ & 19 & 19 & $1.65(0.73-3.75)$ & $1.02(0.36-2.88)$ & 0.97 \\
\hline$>40$ & 8 & 15 & $3.09(1.14-8.44)$ & $2.01(0.57-7.09)$ & 0.28 \\
\hline \multicolumn{6}{|l|}{ Sex } \\
\hline M & 86 & 75 & 1 & & \\
\hline $\mathrm{F}$ & 75 & 39 & $0.59(0.36-0.98)$ & $0.62(0.34-1.12)$ & 0.11 \\
\hline \multicolumn{6}{|l|}{ Marital status } \\
\hline Single & 67 & 38 & 1 & 1 & 1 \\
\hline Married & 87 & 66 & $1.34(0.80-2.23)$ & $1.03(0.52-2.03)$ & 0.93 \\
\hline Divorced \widowed & 7 & 10 & $2.53(0.88-7.16)$ & $1.94(0.55-6.77)$ & 0.30 \\
\hline \multicolumn{6}{|l|}{ Occupation } \\
\hline Government employee & 45 & 39 & 1 & 1 & 1 \\
\hline Merchant & 41 & 31 & $0.87(0.46-1.6)$ & $0.62(0.29-1.30)$ & 0.21 \\
\hline Farmer & 18 & 16 & $1.02(0.46-2.2)$ & $0.41(0.13-1.26)$ & 0.12 \\
\hline Student & 31 & 13 & $0.48(0.22-1.05)$ & $0.36(0.14-0.95)^{*}$ & $0.04^{*}$ \\
\hline Day labor & 10 & 5 & $0.57(0.18-1.83)$ & $0.25(0.06-1.06)$ & 0.06 \\
\hline House wife & 16 & 10 & $0.72(0.29-1.77)$ & $0.36(0.10-1.28)$ & 0.11 \\
\hline \multicolumn{6}{|l|}{ Education } \\
\hline Unable to write \& read & 20 & 23 & 1 & 1 & 1 \\
\hline Read \& write only & 23 & 16 & $0.61(025-1.4)$ & $0.61(0.25-1.45)$ & 0.26 \\
\hline Primary & 19 & 12 & $0.55(0.22-1.4)$ & $0.55(0.22-1.40)$ & 0.21 \\
\hline Secondary & 88 & 53 & $0.52(0.26-1.04)$ & $0.52(0.26-1.04)$ & 0.66 \\
\hline College \& above & 11 & 10 & $0.79(0.27-2.25)$ & $0.79(0.28-2.25)$ & 0.66 \\
\hline \multicolumn{6}{|l|}{ Social support } \\
\hline Excellent & 54 & 32 & 1 & 1 & \\
\hline Very good & 50 & 37 & $1.24(0.67-2.29)$ & $1.28(0.65-2.50)$ & 0.48 \\
\hline Good & 41 & 27 & $1.11(0.57-2.1)$ & $1.13(0.55-2.31)$ & 0.74 \\
\hline Fair \& poor & 16 & 18 & $2.03(0.89-45)$ & $1.58(0.63-4.01)$ & 0.33 \\
\hline \multicolumn{6}{|l|}{ Cause of head injury } \\
\hline Car & 56 & 52 & 1 & 1 & 1 \\
\hline Motor bicycle & 77 & 43 & $0.6(0.35-1.02)$ & $0.54(0.30-0.98)$ & $0.04^{*}$ \\
\hline Fall accident & 23 & 14 & $0.66(0.31-1.4)$ & $0.94(0.39-2.27)$ & 0.90 \\
\hline Other & 5 & 5 & 1.07 (029-0.9) & $1.98(0.47-8.37)$ & 0.35 \\
\hline \multicolumn{6}{|l|}{ Location of head injury } \\
\hline Rt Lateral & 48 & 37 & 1 & 1 & 1 \\
\hline Lt Lateral & 48 & 38 & $1.03(0.561-1.8)$ & $1.01(0.52-1.96)$ & 0.97 \\
\hline Frontal & 42 & 33 & $1.02(0.55-1.9)$ & $1.02(0.51-2.05)$ & 0.95 \\
\hline Other site $e^{* *}$ & 23 & 6 & $0.34(0.12-0.9)$ & $0.28(0.09-0.83)$ & $0.02 *$ \\
\hline
\end{tabular}

${ }^{*} P$ value $\leq 0.05$ (Significant Association), ** Back, occipital and parietal area 


\section{Recommendation}

Future studies better to consider imaging finding of individuals with head injury as supportive data in addition to assessing symptoms included in the PCS tool.

\section{Limitation}

Since the study design is cross-sectional, it does not allow inferring causation.

\section{Additional files}

Additional file 1: Social support of study participants attending emergency outpatient department of Hawassa University comprehensive specialized hospital Hawassa, Southern Ethiopia $(n=289)$ (DOCX $25 \mathrm{~kb})$

Additional file 2: Cause of injures are the study participant attending emergency outpatient department of Hawassa university comprehensive specialized hospital Hawassa, Southern Ethiopia $(n=289)($ DOCX $24 \mathrm{~kb})$

Additional file 3: Symptoms of PCS of study participants attending emergency outpatient department of Hawassa University comprehensive specialized hospital, Hawassa, Southern Ethiopia $(n=289)$ (DOCX $16 \mathrm{~kb})$

\section{Abbreviations}

ACRM: American congruent of rehabilitation medicine; CDC: Center for disease control; Cl: Confidence Interval; DHS: Demographic and Health Survey; DSM: Diagnostic and statistical manual; ED: Emergency department: GCS: Glasgow coma scale; HUCSH: Hawassa University compressive specialized hospital; ICD: International classification of diseases; ICU: Intensive care unite; MTBI: Mild traumatic brain injuries; NGO's: Non-Governmental Organization; NICU: Neonatal intensive care unit; PCD: Post-concessional disorder; PCS: Postconcussion syndrome; PCSS: Post-concussion syndrome scale; PTA: Post traumatic amnesia; RTA: Rode traffic accident; SD: Standard deviation; TBI: Traumatic brain injuries; US: United state

\section{Acknowledgements}

We would like to forward our gratitude to study participants and staffs from Hawassa University Comprehensive specialized hospital for devoting their time to contribute their idea during data collection.

\section{Funding}

No Funding was received for this research work.

\section{Availability of data and materials}

All generated data are included in this article and its supporting information.

\section{Authors' contributions}

$A B$ and $E G$ participated in the conception, design of the study, reviewing the proposal, data analysis and report writing. AB, EG, MA, BD and ZO were participated in data analysis and report writing. $A B$ prepared the manuscript for publication. All authors read and approved the final manuscript.

\section{Ethics approval and consent to participate}

Ethical clearance was obtained from Hawassa University College of medicine and health sciences, Institutional review board. Written consent was obtained from of each study participants. The purpose of this study was explained and confidentiality of the interview results and Anonymity was maintained.

\section{Consent for publication}

Not applicable.

\section{Competing interests}

The authors declare that they have no competing interest.

\section{Publisher's Note}

Springer Nature remains neutral with regard to jurisdictional claims in published maps and institutional affiliations.
Received: 17 October 2018 Accepted: 8 November 2018

Published online: 21 November 2018

\section{References}

1. Mittenberg WSS (2000) Diagnosis of mild head injury and the postconcussion syndrome. J Head Trauma Rehabil 15(2):783-791

2. Association AP (1994) diagnostic and statistical manual of mental disorders, 4th edn. American Psychiatric Association, Washington

3. Jorge RE (2005) Neuropsychiatric consequences of traumatic brain injury: A review of recent findings. Current Opinion in Psychiatry 18(3):289-299.

4. McHugh T, Laforce R, Gallagher P, Quinn S, Diggle PBL (2006) Natural history of the long-term cognitive, affective, and physical sequelae of a minor traumatic brain injury. Brain Cogn 60(2):209-211

5. Bigler ED (2008) Neuropsychology and clinical neuroscience of persistent post-concussive syndrome. Int Neuropsychol Soc 14(1):1-22

6. Ryan LMWD (2003) Post-concussion syndrome. Int Rev Psychiatry 15(4):310-316

7. Manuals M (2003) Concussion. Online medical library

8. Iverson GLLR (2003) Examination of postconcussion-like symptoms in a healthy sample. Appl Neuropsychol 10(3):137-144

9. Sivák S, Kurca E, Jancovic D, KP PS (2005) Contemporary view on mild brain injuries in adult population. Casopis lekaru ceskych 144(7):445-450

10. Hall RC, Hall RCCM (2005) Definition, diagnosis, and forensic implications of post-concessionalsyndrome. Psychosomatics 46(3):195-202

11. Barth JT, EP- P RR (2006) Mild traumatic brain injury: Definitions, Psychological Knowledge in Court: PTSD. Pain and TBI 46(3):271-277

12. RA B (2008) Disentangling mild traumatic brain injury and stress reactions. N Engl J Med 358(5):525-527

13. Lee LK (2007). Controversies in the sequelae of pediatric mild traumatic brain injury. Pediatric Emergency Care 23(8):5803

14. Al J (2014) Et. The epidemiology of hospital-referred head injury. J Sci Res Reports 3(15):2055-2064

15. Bergersen K, Halvorsen JØ, Tryti EA, Taylor SI, Olsen A (2017) A systematic literature review of psychotherapeutic treatment of prolonged symptoms after mild traumatic brain injury. Brain Inj 31:279-289

16. Kifle Woldemichael1 N (2011) Magnitude and pattern of injury. Ethiop J Heal Sci 20(3):155

17. Crawford S, Wenden FJWD (1996) The Rivermead head injury follow up questionnaire: a study of a new rating scale and other measures to evaluate outcome after head injury. J Neurol Neurosurg Psychiatry 60:510-514

18. King NS, Crawford S, Wenden FJ, Moss NE, Wade DT (1995) The Rivermead post concussion symptoms questionnaire: A measure of symptoms commonly experienced after head injury and its reliability. J Neurol 242:587-592

19. Barker-Collo S, Theadom A, Jones K, Ameratunga S, Starkey N, Dudley M et al (2016) Reliable individual change in post concussive symptoms in the year following mild traumatic brain injury: data from the longitudinal, population-based brain injury incidence and outcomes New Zealand in the community (bionic) study. JSM Burn Trauma 1:1-7

20. Awang, Mohamed Saufi BB, Hup CK, Rus RM Post concussion syndrome after mild traumatic brain injury in a single neurosurgical center in East Coast, Malaysia-a preliminary report. Clin Med (Northfield II) 2016, 15:2016

21. Lannsjö M, Af Geijerstam JL, Johansson U, Bring J, Borg J (2009) Prevalence and structure of symptoms at 3 months after mild traumatic brain injury in a national cohort. Brain Inj 23(3):213-219

22. Saulle M, Greenwald BD (2012) Chronic traumatic encephalopathy: a review. Rehabil Res Pract. 2012:816069

\section{Ready to submit your research? Choose BMC and benefit from:}

- fast, convenient online submission

- thorough peer review by experienced researchers in your field

- rapid publication on acceptance

- support for research data, including large and complex data types

- gold Open Access which fosters wider collaboration and increased citations

- maximum visibility for your research: over $100 \mathrm{M}$ website views per year

At BMC, research is always in progress.

Learn more biomedcentral.com/submission 